\title{
EFFECTS OF AGING TIME ON MECHANICAL PROPERTIES OF SAND CAST Al-4.5Cu ALLOY
}

\author{
S.Ilangovan ${ }^{1}$, R.Srikanthan ${ }^{2}$, G. Veda Vyass ${ }^{3}$ \\ ${ }^{I}$ Assistant Professor (SG), Department of Mechanical Engineering, Amrita School of Engineering, Amrita Vishwa \\ Vidyapeetham, Coimbatore, Tamil Nadu, India \\ ${ }^{2}$ Third Year B.Tech, Department of Mechanical Engineering, Amrita School of Engineering, Amrita Vishwa \\ Vidyapeetham, Coimbatore, Tamil Nadu, India \\ ${ }^{3}$ Third Year B.Tech, Department of Mechanical Engineering, Amrita School of Engineering, Amrita Vishwa \\ Vidyapeetham, Coimbatore, Tamil Nadu, India
}

\begin{abstract}
An investigation was carried out to understand the effects of aging time of a cylindrical specimen on hardness, tensile strength and \% elongation of sand cast Aluminium alloy $(\mathrm{Al}-4.5 \mathrm{Cu})$. The alloy was melted in an electric furnace and the molten alloy was poured into sand moulds. The cast rods were tested for Vickers micro-hardness, ultimate tensile strength and \% elongation. The aging time was varied from 4 to 40 hours in steps of 4 hours and the maximum hardness was achieved when the specimen was aged for 36 hours. It was found that the hardness of the alloy decreases when further aging was done. Moreover, it was observed that the tensile strength increases with increase in hardness, whereas the \% elongation decreases.
\end{abstract}

Key Words: Al-4.5Cu, Aging Treatment, Mechanical Properties, Sand cast.

\section{INTRODUCTION}

Aluminium alloys have a wide range of applications in the aerospace and automotive industries. This is mainly due to its advantageous characteristics that include high electrical and thermal conductivities, high ductility, high specific strength, ease of casting, low density, high strength to weight ratio and reasonable corrosion resistance. A relative balance of properties is attained using appropriate heat treatment techniques [1-6] and is exploited by many industries, especially the automotive industry which has recently increased the production of aluminium alloys castings for engine blocks and cylinder heads [6-7].

Copper has been the most common alloying element almost since the beginning of the aluminum industry, and a variety of alloys in which copper is the major addition were later developed. Copper is added to aluminium to increase its strength, hardness, fatigue, creep resistance and machinability [8].

In this work, the cast aluminium alloy of composition Al$4.5 \mathrm{Cu}$ was studied in order to find out the effect of aging time on hardness, tensile strength, \% elongation. This was done to compare the results with as-cast properties of $\mathrm{Al}-4.5 \mathrm{Cu}$ alloy in order to study the enhancement of mechanical properties on aging.

\section{EXPERIMENTAL PROCEDURE}

\subsection{Material Preparation}

Aluminium alloy $(\mathrm{Al}-4.5 \mathrm{Cu})$ castings were produced by melting commercially available pure aluminium ingots and electrolytic copper rods. The appropriate weight percent of the elements were melted in a graphite crucible using an electric furnace in an inert argon atmosphere. The molten metal was poured at a temperature of $720^{\circ} \mathrm{C}$ into sand moulds at room temperature to make rods of $\varnothing 16 \mathrm{~mm}$ and length of 150 $\mathrm{mm}$. The chemical composition of the cast alloy was tested using a spectrometer and the results are reported in Table 1.

Table -1: Cast alloy composition

\begin{tabular}{|l|l|l|}
\hline Al & $\mathbf{C u}$ & Others \\
\hline 94.5 & 4.5 & 1 \\
\hline
\end{tabular}

\subsection{Microstructure}

The microstructure of the alloy was observed through optical microscope in various stages of aging process. The specimen was prepared for microscopic observation using standard metallographic techniques. The etchant used was Krolls Reagent (92\% Distilled Water, 6\% Nitric Acid, 2\% HF). The photographic image of the optical microscope is shown in Figure 1. 


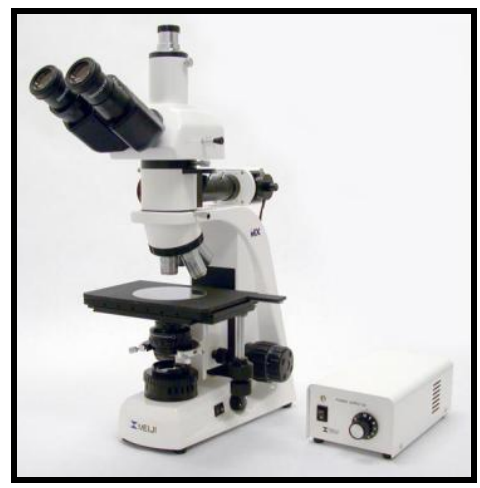

Fig-1: Image of Optical Microscope

\subsection{Hardness Testing}

To assess the effect of aging heat treatment, the hardness of the all the specimens were measured using a micro-hardness tester as shown in Figure 2. A number of readings were taken at different locations for each specimen and an average value was calculated. The specimens were prepared and tested as per ASTM- E384 standard. The parameters used in this test were: $50 \mathrm{gm}-\mathrm{f}$ applied load and $20 \mathrm{~s}$ duration. The hardness values varied in each sample was within $\pm 5 \mathrm{HV}$.

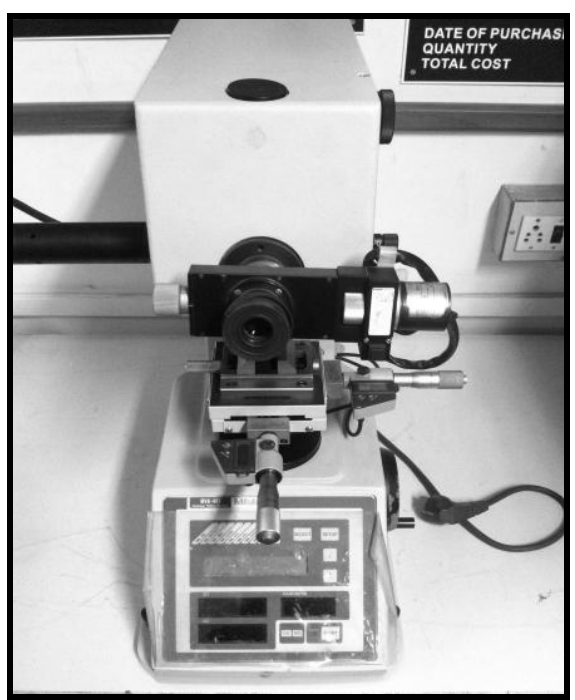

Fig-2: Mitutoyo make micro-hardness tester

\subsection{Tensile Testing}

The tensile test was conducted to predict the tensile strength (TS) of the material as well as to find the ductility in terms of $\%$ elongation of the alloy. The test specimens were prepared according to ASTM - E4 standard as shown in Figure 3. The photographic image of the specimen is shown in Figure 4. The specimens were tested using computerized universal testing machine (Make: Tinius Olsen M25KT) as shown in Figure 5.

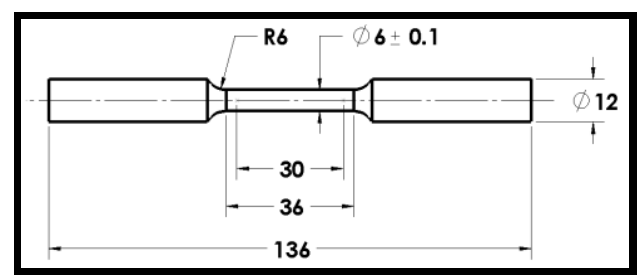

Fig-3: Drawing of Tensile Test Specimen

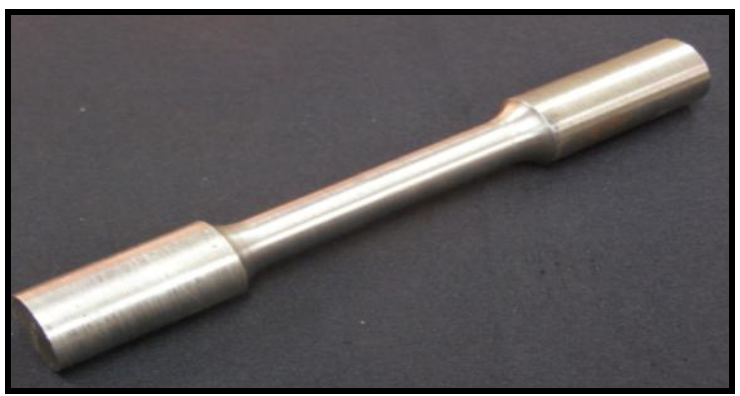

Fig-4: Photograph image of tensile test specimen

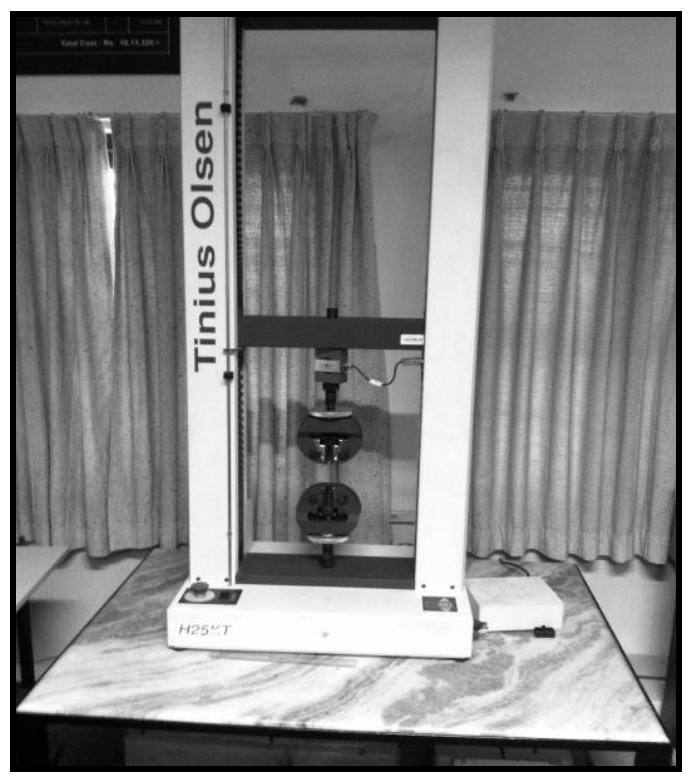

Fig-5: Universal tensile testing machine

\section{RESULTS AND DISCUSSION}

\subsection{Microstructure}

Age hardening characteristics are evident in $\mathrm{Al}-\mathrm{Cu}$ aluminum alloy; with an increase in aging time, the mechanical strength of the alloy increased considerably and dropped gradually after a maximum value of aging time. Effect of aging is affected by various factors viz. solid solution strengthening, substrate's recovery and recrystallization and new phase precipitation. The first two factors lower the strength of the alloy with the increase in aging time, but phase precipitation 
strengthens the alloy. The microstructures obtained are shown in Figure 6(a-c) with a magnification of $20 \mu \mathrm{m}$.

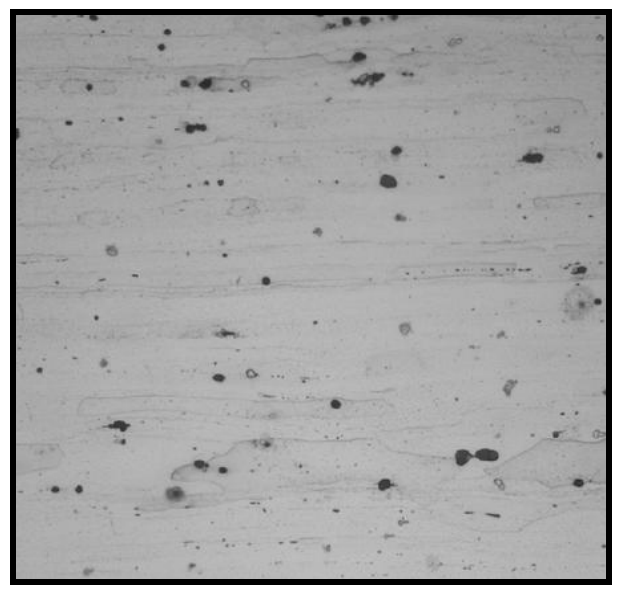

Fig-6a: Microstructure of as-cast Al-4.5Cu alloy

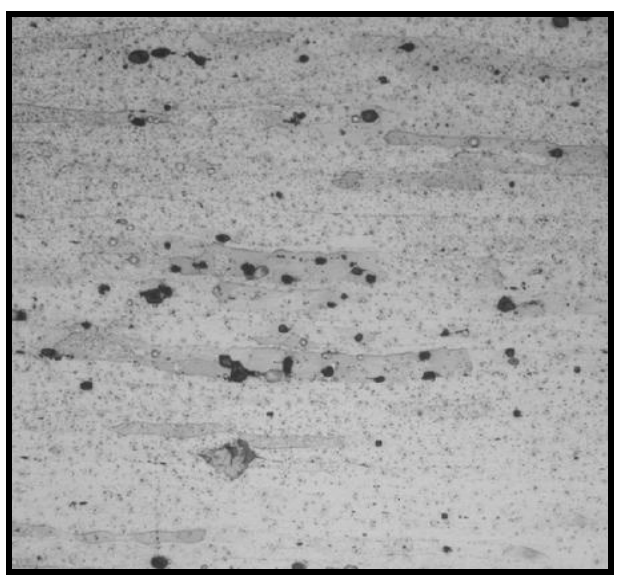

Fig-6b: Microstructure of 16 hours age-hardened specimen

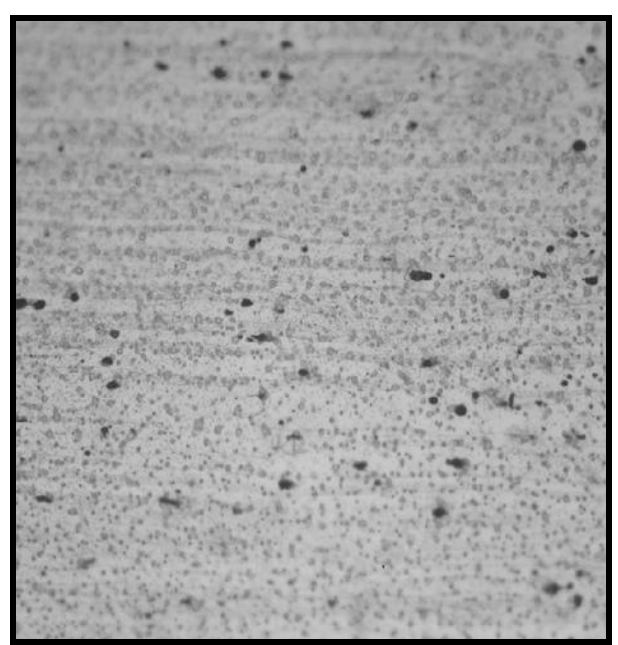

Fig-6c: Microstructure of 36 hours age-hardened specimen

\subsection{Hardness}

The influence of aging time on hardness is shown in Figure 7. It was observed from the plot that the hardness of the specimen increases from $70 \mathrm{HV}$ to $154 \mathrm{HV}$ maximum as the aging time increased from 0 to 36 hours. The hardness value decreases upon further aging. The increase in hardness was due to the formation of precipitates which interacted with the dislocation movements. The decrease in hardness might have been due to over-aging of the specimen. Therefore it maybe concluded that the hardness increases with increasing aging time up to a certain limit which depends on the alloy composition and aging temperature. It was found to be consistent with previous reports [9-11].

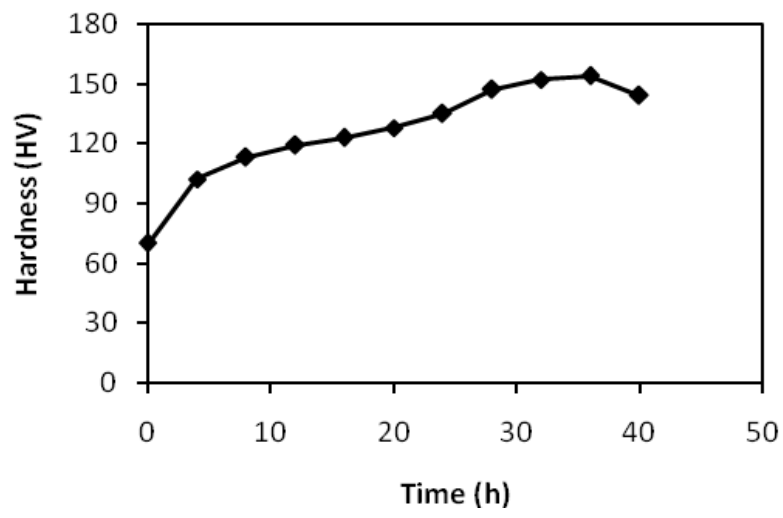

Fig-7: Hardness versus aging time

Figure 8 shows the variation of $\%$ elongation with hardness of the alloy as a function of aging time. As stated above the hardness of the alloy increases with aging time. Generally, \% elongation decreases with increasing hardness. The same behaviour was obtained in this study. Hence it maybe concluded that the \% elongation varies inversely with hardness of the alloy.

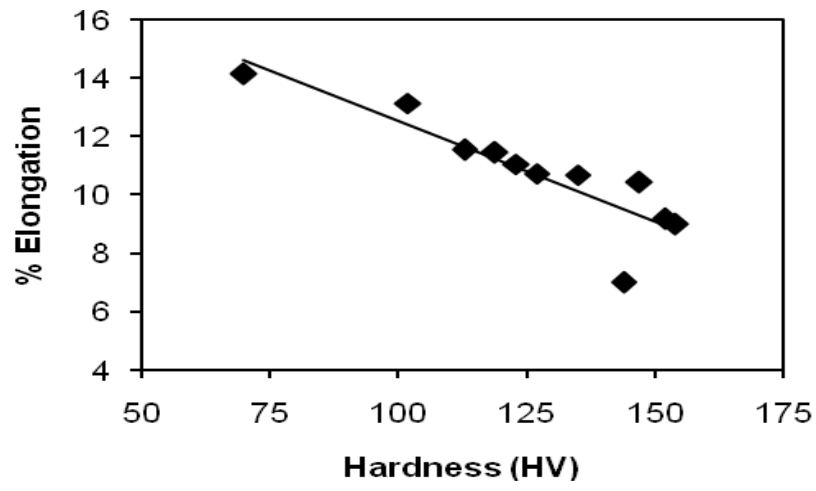

Fig-8: \% Elongation versus hardness 


\subsection{Tensile Strength}

Figure 9 shows the variation of Tensile strength with aging time. It is seen that the tensile strength of the alloy increases from 147.5 to $226 \mathrm{MPa}$ as time increases from 0 to 36 hours. It is observed that the tensile strength value decreases to 217 $\mathrm{MPa}$ with further aging treatment. It may be due to overaging.

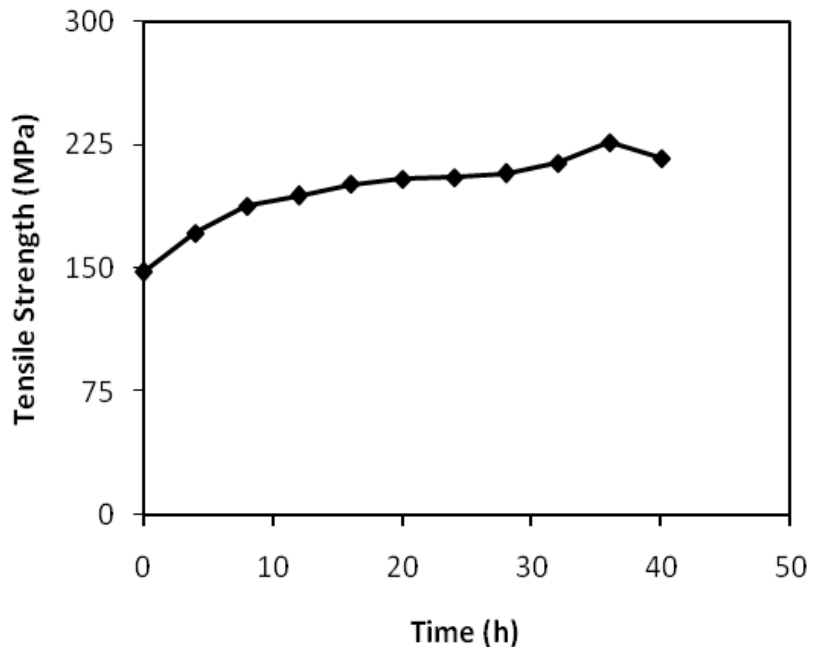

Fig-9: Tensile strength versus aging time

Figure 10 shows the variation of tensile strength with the hardness of the alloy. It was found that the tensile strength inreases with increase in hardness of the specimen. Hence it maybe concluded that the tensile strength is a linearly varying function of the hardness of the alloy.

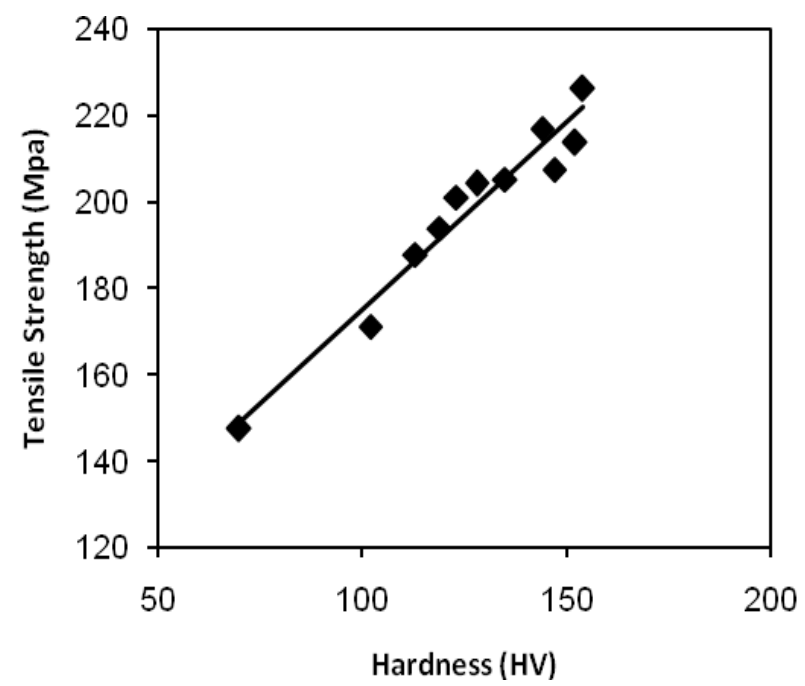

Fig-10: Tensile Strength versus hardness

\section{CONCLUSIONS}

The findings of this particular experiment are summarised as follows:

- The hardness increases with aging time up to a particular aging time which depends on the alloy composition and aging temperature.

- The \% elongation decreases as the hardness of the alloy increases.

- The tensile strength of the alloy increases gradually with increase in aging time up to a specific aging time.

- The tensile strength is found to increase linearly with increase in hardness of the alloy.

\section{REFERENCES}

[1] Wislei.R.Osorio,Daniel, J..Moutinho, Leandro C.Peixoto, Ivaldo L.Ferreira, Amauri Garcia (2011), "Macro segregation and microstructure dendritic array affecting the electrochemical behavior of ternary AlCu-Si alloys", Electrochimica Acta, Vol. 56, pp. 84128421.

[2] G.A.Capuano and W.G.Davenport, "Electrodeposition of Aluminium from Alkyl Benzene Electrolytes", Journal of The Electrochemical Society, Vol.118, Issue 10, pp. 1688-1695.

[3] Mortaza Azarbarmas, Masoud Emamy, Jafar RasizaDeh, Mohammed Alipour, Mostafa Karamouz (2011), "The effects of Be on Mechanical Properties of $\mathrm{Al}-\mathrm{Mg}_{2} \mathrm{Si}$ in situ composite", The Minerals, Metals and Materials Society.

[4] V.V.Krisyuk, L.Aloui, N.Prud Home, B.Saraprata, F.Senocq, D.Samelor and C.Vahlas (2009), "CVD of Pure copper Films from a novel Amidinate Precursor", The Electrochemical Society, Vol. 25, pp. 581-586.

[5] G. García-García, J. Espinoza-Cuadra, H. ManchaMolinar (2007), "Copper content and cooling rate effects over second phase particles behavior in industrial aluminum-silicon alloy 319", Mater Des, Vol. 28, pp. 428-433.

[6] A.M.Samuel, F.H.Samuel, H.W.Doty (1996), "Observations on the formation of $\beta-\mathrm{Al}_{5} \mathrm{FeSi}$ phase in 319 type Al-Si alloys", Journal of Materials Science, Vol.31, pp. 5529-5539.

[7] I.Guillot, B.Barlas, G.Cailletaud, M.Clavel, D.Massinon (2002), "Thermomechanical fatigue and aging cast aluminium alloy: A link between numerical modeling and microstructural approach", International Conference on Temperature-Fatigue Interaction, Vol.29, pp. 75-84.

[8] E.L.Rooy, Metals Handbook, vol. 15, ASM International, Materials Park, Ohio.1988, pp. 743.

[9] Ilangovan, S. and Sellamuthu, R. (2012), “An Investigation of the effect of Ni Content and Hardness on the wear behavior of Sand Cast Cu-Ni-Sn Alloys", International Journal of Microstructure and Materials Properties, Vol.7, pp.316-328. 
[10] Ilangovan, S. and Sellamuthu, R. (2013), "Effects of Tin on Hardness, Wear Rate and Coefficient of Friction of Cast $\mathrm{Cu}-\mathrm{Ni}-\mathrm{Sn}$ Alloys", Journal of Engineering Science \& Technology, Vol.8, No.1, pp. 44-54.

[11] Dongmei Zhao, Q.M. Dong, P. Liu, B.X. Kang, J.L. Huang, Z.H. Jin (2003), "Aging behavior of $\mathrm{Cu}-\mathrm{Sn}$ Alloy", Materials Science and Engineering A, Vol.361, pp. 93-99.

\section{BIOGRAPHIES}

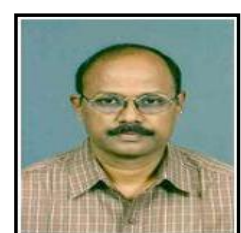

Dr. S. Ilangovan has completed his Bachelor's Degree in Mechanical Engineering and Master's Degree in Production Engineering. He has fourteen years of experience in industry and sixteen years in teaching. He has also completed

Ph.D. in Materials Engineering

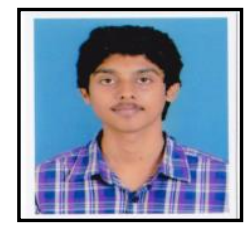

R. Srikanthan is a third-year Mechanical Engineering student currently pursuing Bachelor of Technology degree from Amrita Vishwa Vidyapeetham, Tamil Nadu.

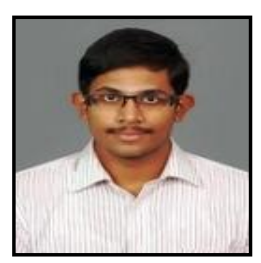

G. Veda Vyass is a third-year Mechanical Engineering student currently pursuing Bachelor of Technology degree from Amrita Vishwa Vidyapeetham, Tamil Nadu. 